International Journal of Social Science And Human Research

ISSN(print): 2644-0679, ISSN(online): 2644-0695

Volume 05 Issue 01 January 2022

DOI: 10.47191/ijsshr/v5-i1-08, Impact factor-5.586

Page No: 50-55

\title{
Student's Perceptions of the Use of CBT for the Conduct of General Studies (GST) Examinations in Usmanu Danfodiyo University, Sokoto
}

\author{
BAWA, Nura ${ }^{1}$, BASHAR, Maryam ${ }^{2}$ \\ ${ }^{1}$ Department of Curriculum Studies and Educational Technology, Faculty of Education and Extension Services, Usmanu Danfodiyo \\ University, Sokoto, Nigeria. \\ ${ }^{2}$ Department of Adult Education and Extension Services, Faculty of Education and Extension Services, Usmanu Danfodiyo \\ University, Sokoto, Nigeria.
}

\begin{abstract}
The paper investigated the students' perceptions of the use of CBT for the conduct of General Studies (GST) examinations in Usmanu Danfodiyo University, Sokoto. The study employed a descriptive survey design. All the 5600 undergraduate students who sat for GST examinations during the 2019/2020 academic session formed the population of the study. The Israel Model (2013) was used to determine 372 students as the sample size for the study. An instrument titled "Students' Perceptions of Writing CBT Examination" (SPWCBTE) was used for the data collection. The instrument was validated, a pilot study was conducted, and a reliability index of 0.95 was obtained. Results from the study revealed that the students have positive views on the CBT examinations. Some of the problems confronted by students during the examinations, as indicated by the results, include system errors, login issues, and the slow nature of the systems during submission. The study concluded that the students have positive views of the CBT examinations in the university. It was recommended that the university management should be organizing presentations and workshops to promote the CBT system. Majors should be taken to ensure quality assurance and control of the ICT facilities during and after the conduct of examinations.
\end{abstract}

KEYWORDS: Computer-based test; general studies; perceptions; examination

\section{INTRODUCTION}

Paper-based tests were the only method available to educators and instructors for a long time, until the arrival of computers, who jotted down a set of questions on a piece of paper, then distributed these papers to learners, waiting for them to complete and submit the test before the instructors could grade the tests, write feedback, and prepare reports. It was a time-consuming job until the arrival of technology-based evaluation systems, which rendered pen and paper obsolete and gradually gave way to a better, more effective assessment system (Hew, Jia, Gonda, \& Bai, 2020). Exams and tests are an important element of the teaching/learning process in education since they allow the teacher to assess pupils during the course and at the end. The extent to which the teacher's educational objectives have been met is determined via tests.

Exams can also assist teachers in evaluating and assessing students to determine whether they are learning what is expected of them. Paper-pencil based assessments are the most common technique of assessing pupils' academic achievement in most schools. Fortunately, the rapid growth of Information and Communication Technologies (ICTs) in teaching/learning has transformed the paradigm of examination from paper-pencil to computer-based tests (Okocha, Eyiolorunshe, \& Owolabi, 2017).

According to Soto-Rodrguez, Fernández-Vilas, and Daz-Redondo (2021), computer-based evaluation can help students develop abilities like scientific processing as well as the ability to plan and execute scientific research. Computer testing is more efficient than paper-based testing because it allows for year-round testing, scheduling flexibility, and speedier score reporting, among other benefits. Computer-based testing (CBT) has been discovered to have numerous advantages in terms of test administration. Improved security, access to interactive item formats, and quick scoring are just a few of the advantages (Soto-Rodríguez, Fernández-Vilas, \& Díaz-Redondo, 2021). The computer allows for flexible scheduling, allowing examinees to take tests at their leisure at nearly any time (Nugroho, Kusumawati, \& Ambarwati, 2017). While taking the test, examinees are given feedback on the correctness of their responses to each question.

In educational settings, computer-based examinations provide students with pleasant contacts or communication opportunities, as well as the ability to obtain fast feedback. It is also cost-effective, and the widespread availability of powerful 


\section{Student's Perceptions of the Use of CBT for the Conduct of General Studies (GST) Examinations in Usmanu Danfodiyo University, Sokoto}

computers in educational settings makes computer-based testing both viable and appealing (Jimoh, Shittu, \& Kawu, 2012). CBT also allows test takers to take their exams at any time and from any location.

Despite its many advantages, CBT has some disadvantages. Errors can occur when using a response entry device, such as a keyboard, touch screen, or mouse. Because of their anxiety, examinees may press the wrong key in response to questions, resulting in an error and risking the validity of the examinee's result. The time difference between a person's input and the computer's following response might also be problematic. According to Mills (2015), long time intervals between responses might contribute to negative user attitudes, anxiety, and poor performance. Examinees may give correct answers that the system misses, leading in worse reliability and discrimination indices.

Another important factor that may influence the effective use of computers for assessment is ICT skills. The ability levels of a learner affect how effectively they can handle CBT. ICT skill levels are split into three (3) categories, according to Hains (2021): basic, intermediate, and proficient. Level 1 is the most fundamental level, requiring only the bare minimum of abilities and skills to function. At this level, a teacher can only perform the very minimum functions required to operate the hardware/software. Level 2 teachers are 'average-to-competent,' which means they can cover the basics plus a little more. The majority of your teaching team should be at this level. At this level, a teacher can easily do the fundamentals, as well as demonstrate other abilities that a school would want, so increasing their efficacy and productivity. Level 3 is the best level for a professional, technologically competent instructor who demonstrates efficient adaptation across all critical areas. In terms of professional ICT development, schools should aim for teachers who are between Level 2 and Level 3.

Hundreds of admissions, placement, certification, and licensure testing programs assessments and examinations are now administered on computers in some Nigerian tertiary institutions, with the number growing each year as a result of the migration from paper-based testing (PBT) to computer-based testing. Because a single set of tests or assessments may be taken on multiple devices at the same time, online assessment is critical in education. The responses can be automatically graded and scored in an auto-generated report. Although a single set of tests cannot be done on two devices at the same time, the replies are saved in a database, grades are awarded manually, and the report is generated afterwards. However, as effective and desirable as computerbased assessment has been, it has been built on the assumption that students display what they know and can accomplish, but construct irrelevant elements like disengagement, test anxiety, and cheating pose a danger to the validity of inferences (Manurung, Fildzah, \& Rajagukguk, 2019).

The use of computer-based testing versus paper-based testing appears to benefit both the states that administer the assessment programs and the students who participate in them. According to Ladimeji, Yebola, Christopher, and Annenne (2017), in their study on students' perceptions of computer-based tests in Nigerian universities, students gave CBT a positive rating on perceived usefulness (64.3 percent), ease of use (66.1 percent), and credibility (67 percent), and the study concluded that students thought CBT was useful, easy to use, and credible. Some Nigerian universities, such as Usmanu Danfodiyo University in Sokoto, have acknowledged these benefits. This is one of the University's most recent initiatives aimed at encouraging students to get handson experience and reducing other sorts of examination malpractice. The General Studies (GS) division was the first institution in the University to implement CBT. Despite the fact that a computer-based test may be a step in the right direction, several variables must be considered before kids are exposed to the testing method. Students' opinions must be heard because they determine the program's effectiveness. Since the use of CBT for the conduct of examinations in the unit has already begun, it is necessary to research students' perspectives on the use of CBT for the conduct of examinations in the unit.

\section{PURPOSE OF THE STUDY}

The following objectives are formulated to guide the study:

1. To ascertain the ICT skill level of the undergraduate students of Usmanu Danfodiyo University, Sokoto.

2. To determine the perception of undergraduate students on the use of CBT for GSts in Usmanu Danfodiyo University, Sokoto.

3. To ascertain the challenges the students face during the CBT for GSts in Usmanu Danfodiyo University, Sokoto.

\section{RESEARCH QUESTIONS}

1. What is the ICT skill level of the undergraduate students of Usmanu Danfodiyo University, Sokoto?

2. What is the perception of undergraduate students on the use of CBT for GSts in Usmanu Danfodiyo University, Sokoto?

3. What are the challenges the students face during the CBT for GSts in Usmanu Danfodiyo University, Sokoto?

\section{METHODOLOGY}

The design adopted for this study was descriptive of a survey type. This form of research design enables researchers to cover a large number of respondents and utilize data collected the way it is without any manipulation. The population for this study was all the 5600 undergraduate students of Usmanu Danfodiyo University, Sokoto. 372 undergraduate students were selected as samples for 


\section{Student's Perceptions of the Use of CBT for the Conduct of General Studies (GST) Examinations in Usmanu Danfodiyo University, Sokoto}

the study as guided by Israel Model (2013) for determination of sample size. A researcher-structured questionnaire pegged "students' perceptions to CBT" was used to obtain necessary information from the respondents. The instrument was a four likers scale of Disagree (D), Strongly Disagree (SD), Agree (A), and Strongly Agree (SA). It consisted of two sections, section A and B. Section A solicited information on the bio- data of the respondents, and section B solicited information on students' perceptions to CBT. To ascertain the level of consistency of the instrument, after the validation, a pilot study was conducted and a reliability index of 0.80 was obtained. The collected data were analyzed using descriptive statistics. The descriptive statistic used to answer the research questions includes percentages and a bar chart.

Research Question 1: What is the ICT skill level of the undergraduate students of Usmanu Danfodiyo University, Sokoto?

\section{ICT BASIC SKILL LEVELS}

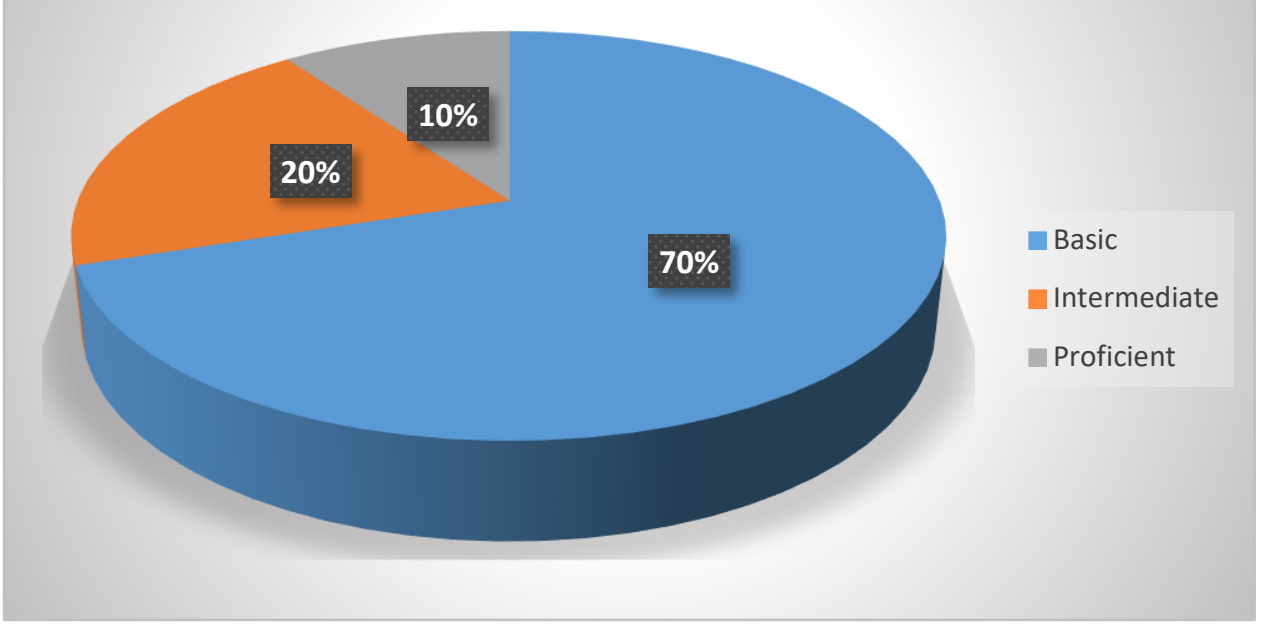

The above figure/chart represents the results of the Usmanu Danfodiyo University, Sokoto undergraduate students' ICT skill levels as revealed by the study. From the chart, it could be seen that $70 \%$ of the students are at the basic level of ICT skill, $20 \%$ at the intermediate level, and $10 \%$ at the proficient level.

Research Question 2: What is the perception of undergraduate students on the use of CBT for GSts in Usmanu Danfodiyo University, Sokoto?

Table 1: Students' perceptions of CBT

\begin{tabular}{|c|c|c|c|c|c|}
\hline $\mathbf{S} / \mathbf{N}$ & ITEM & $\mathbf{S A}$ & $\mathbf{A}$ & D & SD \\
\hline 1 & I have a phobia of writing exams via ICT devices & - & - & 50 & 50 \\
\hline 2 & I feel the CBT is better than paper-based exam & 60 & 30 & 10 & - \\
\hline 3 & CBT is easier than the paper-based exam & 30 & 40 & 30 & - \\
\hline 4 & I feel confident when writing exams via computer & - & 60 & 40 & - \\
\hline 5 & The software used for the CBT is user friendly & 70 & 20 & 10 & - \\
\hline 6 & I wish all exams would be written via computer & - & 80 & 20 & - \\
\hline 7 & Use of CBT facilitates quick release of results & 100 & - & - & - \\
\hline 8 & Writing exams via computer is a bold step to curtailing exams malpractice. & 70 & 30 & - & - \\
\hline 9 & CBT helps to reduce errors committed during results compilation & 40 & 60 & - & - \\
\hline 10 & CBT is faster than the paper-based exams, thus it saves a lot of time. & 80 & 20 & - & - \\
\hline 11 & $\begin{array}{l}\text { There are usually no distractions that constitute a nuisance when using CBT } \\
\text { for examination. }\end{array}$ & 30 & 70 & - & - \\
\hline 12 & The speed of using CBT for examination is satisfactory & - & 30 & 70 & - \\
\hline 13 & CBT enhances my effectiveness in academics & 70 & 10 & 20 & - \\
\hline 14 & I am not comfortable to take CBT & - & 50 & 30 & 20 \\
\hline 15 & CBT gives me greater control over my academics & 70 & 10 & 10 & 10 \\
\hline 16 & Using CBT is often frustrating & - & 10 & 20 & 70 \\
\hline 17 & CBT gives me the opportunity to revisit all my attempts. & 50 & 50 & - & - \\
\hline
\end{tabular}

From the results, it is revealed that all the respondents have no phobia of using ICT devices, and feel confident when writing examination via a computer. $60 \%$ representing majority of the respondents strongly agreed that the CBT is better than paper- 


\section{Student's Perceptions of the Use of CBT for the Conduct of General Studies (GST) Examinations in Usmanu Danfodiyo University, Sokoto}

based examination. Furthermore, the result as agreed by $70 \%$ of the respondents indicated that the CBT is easier than paper-based examination. In line with the results, the respondents reported that the software used for CBT in Usmanu Danfodiyo University, Sokoto is user-friendly and wish that all other examinations hold via computers.

In terms of effectiveness, the results showed that $100 \%$ of the respondents are of the opinion that CBT facilitates quick release of results, and also adopting it could be a bold step to reducing examination malpractice in the University. As the results indicated, while CBT helps in reducing errors committed during results compilation as indicated by $100 \%$ of the respondents, writing examinations computer-based also help save students' as well as invigilators' time during the conduct of examinations. The results as unanimously agreed by $100 \%$ of the respondents indicated that CBT gives students the opportunity to revisit all their attempts and make modification where necessary before submission.

As shown by the results, $100 \%$ of the respondents agreed that there are usually no distractions that constitute a nuisance when using $\mathrm{CBT}$ for examination. As the results have it, $70 \%$ representing majority of the respondents opined that $\mathrm{CBT}$ gives them greater control over their academic activities.

Research Question 3: What are the challenges the students face during the CBT for GSts in Usmanu Danfodiyo University, Sokoto?

Table 2: Challenges students faced during CBT

\begin{tabular}{|c|c|c|c|c|c|}
\hline $\mathbf{S} / \mathbf{N}$ & ITEM & SA & $\mathbf{A}$ & D & SD \\
\hline 1 & I experienced login problems & 50 & 20 & 20 & 10 \\
\hline 2 & Slow nature of the systems used for CBT & - & 50 & 50 & - \\
\hline 3 & Inconsistency of power supply & 80 & 20 & - & - \\
\hline 4 & Delay in the commencement of examination & 60 & 20 & 20 & - \\
\hline 5 & Inadequacy of ICT facilities for all students to write exams at the same time. & 100 & - & - & - \\
\hline 6 & Lack of stations for students before the commencement of examinations. & 100 & - & - & - \\
\hline 7 & Anxiety affects me during CBT & 50 & 50 & - & - \\
\hline 8 & I often become depressed during CBT & 30 & 70 & - & - \\
\hline
\end{tabular}

Based on the data collected for the study, it was gathered that among the challenges the undergraduate students experienced during CBT include: login problems; inconsistency of power supply; delay before the commencement of examinations; inadequacy of ICT facilities to accommodate all students at once; lack of conducive station for students while waiting for the commencement of examination; anxiety; and depression. The results also revealed a divided opinion on the wellbeing of the facilities (computers) used for the CBT. While $50 \%$ of the respondents agreed that the systems are too slow, the other half rejected the statement.

\section{DISCUSSION OF FINDINGS}

According to the findings of the survey, undergraduate students at Usmanu Danfodiyo University in Sokoto have varying levels of ICT proficiency. While the majority of them had basic ICT abilities, just a small percentage of them had intermediate or advanced ICT skills. This discovery is not surprising, as several studies have demonstrated that a big proportion of undergraduate students in 21st-century colleges are digital natives who adore technology and its use (Prensky, 2001; Kivunja, 2014; Riegel \& Mete, 2018).

According to the findings of the survey, all of the respondents have no fear of using ICT gadgets and are comfortable writing exams on a computer. This could be due to the fact that the respondents strongly believe that the CBT is superior than the paper-based examination and that the CBT is simpler. This finding supports Idhalama, Odem, and Dime's (2020) assertion that students of this generation want to continue learning using modern technological devices, and thus recommended that government and school administrators encourage the use of CBE/CBT and other ICT facilities to expedite instructional processes among students. In line with the results, the respondents expressed that the software used for CBT in Usmanu Danfodiyo University, Sokoto is user-friendly and wished that all other examinations hold through the use of computers.

In terms of effectiveness, respondents agreed that CBT speeds up the distribution of results and that adopting it may be a bold move toward minimizing examination malpractice at the university. It was also discovered that CBT aids in the reduction of errors made during the compilation of results, and that writing exams on a computer saves both students and invigilators time during the examination process. These findings support Oyero's (2021) findings that computer-based tests have a lot of promise and benefits when compared to traditional evaluation methods. These potentials as indicated by Oyero (2021) include time management, simplicity, curtailing examination malpractice and so on.

According to the findings, login problems, inconsistency of power supply, delays before the start of examinations, inadequacy of ICT facilities to accommodate all students at once, lack of conducive stations for students while waiting for the start of examinations, anxiety, and depression were among the challenges faced by undergraduate students during CBT. This finding is in line with Ogechukwu's (2019) findings that some challenges, such as a lack of infrastructural facilities, insufficient accommodation, equipment, power outages, and examinee incompetence, among others, impacted senior secondary school entrants' 


\section{Student's Perceptions of the Use of CBT for the Conduct of General Studies (GST) Examinations in Usmanu Danfodiyo University, Sokoto}

academic performance during the CBT Jamb examinations in 2018. The findings of this study also support those of Adepoju (2016), who reported that delays before the start of the examination, inconsistent internet networks throughout the examination, power outages during the examination, and unfavorable examination settings are among the obstacles of CBT.

\section{CONCLUSION}

Most of the undergraduate students in the 21st century are digital natives who prefer to use technology in all they do, including the writing of examinations. Although some of them may oppose the innovation, the fact remains that these students must have 21stcentury skills in order to be relevant in their workplaces and functional members of society. These skills include critical thinking, problem solving, ICT literacy, and so on. One of the ways the university could come in to facilitate the acquisition of this set of skills is by subjecting students to writing examinations via computers. This would help motivate the students to acquire more ICT skills.

\section{RECOMMENDATIONS}

In line with the findings of the study, the following are recommended:

1. The university management should be organizing presentations and workshops to promote the CBT system.

2. Universities in Northwestern Nigeria should strategically migrate all the lower level examinations to CBT. This is with the assumption that the universities possess the same characteristics as Usmanu Danfodiyo University, Sokoto.

3. To ensure efficiency and effectiveness in the conduct of CBT, all ICT-related challenges should be carefully studied and addressed by university management. This would help to provide a lasting solution to possible problems that might comeup during the conduct of examinations.

4. Major steps should be taken to ensure quality assurance and control of the ICT facilities during and after the conduct of examinations.

\section{REFERENCES}

1) Adepoju, O. (2016). Challenges encountered in the first general computer based test. PJERE, 1(1), 1-13.

2) Hains, M. (2021). Computer applications technology: Preferred ICT skill levels for teachers. Retrieved from MH Teacher ICT Development: https://matthewhains.online/ict-skills-teachers/

3) Hew, K. F., Jia, C., Gonda, D. E., \& Bai, S. (2020). Transitioning to the "new normal" of learning in unpredictable times: pedagogical practices and learning performance in fully online flipped classrooms. International Journal of Educational Technology in Higher Education, 17(57), https://doi.org/10.1186/s41239-020-00234-x.

4) Idhalama, O. U., Odem, O. K., \& Dime, A. I. (2020). Behavioural tendencies of LIS undergraduates towards computer based examinations (CBE) in Nigeria. International Journal of Library and Information Studies , 10(3), 117-129.

5) Jimoh, R. G., Shittu, A. K., \& Kawu, K. Y. (2012). Students' perception of computer based test (CBT) for examining undergraduate chemistry courses. Journal of Emerging Trends in Computing and Information Sciences, 3(2), 125-130.

6) Kivunja, C. (2014). Theoretical perspectives of how digital natives learn. International Journal of Sustainability in Higher Education, 3 (1), 94-109. DOI: 10.5430/ijhe.v3n1p94.

7) ladimeji, O. F., yebola, A. S., Christopher, O., \& Annenne V. J. P. (2017). Students' perceptions of computer-based test in Nigerian universities. Nigerian Journal of Educational Technology,, 1(2), 117-129.

8) Manurung, A., Fildzah, A., \& Rajagukguk, J. (2019). Computer Based Test (CBT) System for Student Academic Examination. Proceedings of The 5th Annual International Seminar on Trends in Science and Science Education, AISTSSE 2018, 18-19 October 2018, Medan, Indonesia, 10.4108/eai.18-10-2018.2287186.

9) Nugroho, R. A., Kusumawati, N. S., \& Ambarwati, O. C. (2017). Students' perception on the use of computer based test. 2nd International Conference on Innovation in Engineering and Vocational Education25-26 October 2017, Manado, Indonesia, 306012103.

10) Ogechukwu, O. F. (2019). Challenges of 2018 computer based test (cbt) jamb examination for senior secondary school students' acadeamic performance in Anambra State, Nigeria. Okoye Faith Ogechukwu CHALLENGES OF2018 COMPUTER BASED TEST (CBT)JAMB EXAMINATION FOR SENIOR SECONDARY SCHOOL STUDEEuropean Journal of Education Studies, 6(3), 266-277.

11) Okocha, F., Eyiolorunshe, T., \& Owolabi, S. (2017). Student perception and acceptance of computer based testing: A case study of Landmark University students. Journal of Digital Innovations \& Contemporary Reseasrch in Science, Engeneering \& Technology, 5(1), 25-32.

12) Oyero, S. (2021). How Computer Based Tests are Reducing Examination Malpractices in Nigeria. Retrieved from Cresthub: https://cresthub.com/how-computer-based-tests-are-reducing-examination-malpractices-in-nigeria/

13) Prensky, M. (2001). Digital natives, digital immigrants Part 1. On the Horizon, 9(5), 1-6. doi:10.1108/10748120110424816. 
Student's Perceptions of the Use of CBT for the Conduct of General Studies (GST) Examinations in Usmanu Danfodiyo University, Sokoto

14) Riegel, C. \& Mete, R. (2018). Educational technologies for k-12 learners: what digital natives and digital immigrants can teach one another . Educational Planning, 24(4), 49-58.

15) Soto-Rodríguez, E. A., Fernández-Vilas, A., \& Díaz-Redondo, R. P. (2021). Impact of Computer-Based Assessments on the Science's Ranks of Secondary Students. Applied Science, 11, 6169. https://doi.org/10.3390/app11136169. 